\title{
New Development of the J-Based Fracture Testing Technique for
} Ceramic-Matrix Composites

\author{
Toshiyuki Hashida ${ }^{*,+}$ and Victor C. Li \\ Advanced Civil Engineering Materials Research Laboratory, Department of Civil and Environmental Engineering. \\ The University of Michigan, Ann Arbor, Michigan 48109-2125
}

Hideaki Takahashi

Research Institute for Fracture Technology, Tohoku University, Sendai, 980, Japan

\begin{abstract}
The $J$-based fracture testing technique is newly extended to experimentally determine the tension-softening $(\sigma-\delta)$ relations in ceramic-matrix composites. The $J$-based technique originally proposed for concrete has been well established for quasi-brittle materials where the fracture process is primarily dominated by the formation of a fracture process zone and the contribution of the crack tip toughness is negligibly small. In this study, the $J$-based technique is further developed to cover a more general case, i.e., a material in which the crack tip stress singularity coexists with the fracture process zone. This is the case, in particular, for modern fiber-reinforced ceramic composites and coarse-grained ceramics. The newly derived testing technique has been applied to foam glass composites reinforced with $\mathrm{SiC}$ and stainless steel short fibers. The validity of the deduced tension-softening relations has been examined by microscopy observations and by comparing with other conventional testing methods: the fracture energy method and the $R$ curve approach. It is suggested that the $J$-based fracture testing technique can provide reasonable tension-softening relationships and fracture parameters in modern ceramics and ceramic-matrix composites.
\end{abstract}

\section{Introduction}

$\mathbf{C}$ ERAMIC-MATRIX composites have been the focus of substantial research efforts in recent years. The major driving force for ceramic-matrix composite development is the potential of utilizing ceramics in load-carrying structural components with greater mechanical and thermal reliability. A feasible approach for improving mechanical properties is through the enhancement of fracture toughness. It has been established that fiber reinforcement of ceramics is one of the most promising ways to substantially improve fracture toughness and crack growth resistance. ${ }^{1-3}$ Fiber bridging in a zone immediately behind the crack tip is a primary mechanism for the improvements. The bridging zone is often referred to as the fracture process zone. It has been shown from microscopy observations ${ }^{4-6}$ that fracture behavior within the fracture process zone is complicated, and includes fiber debonding, pullout, and breakage.

A Barenblatt-type cohesive model ${ }^{7}$ has been frequently employed to describe the development of the fiber bridging zone in ceramic-matrix composites. ${ }^{4 . K-10}$ Fiber bridging may be

A. Evans-contributing editor

Manuscript No. 195621. Received June 3, 1992; approved November 9. 1993

Research at the ACE-MRL has been supported by a grant from NSF (Program Manager: Dr. K. Chong) to the University of Michigan, Ann Arbor.

"Member, American Ceramic Society.

'On leave from the Research Institute for Fracture Technology, Tohoku University, Sendai 980 . Japan. characterized by the relationship between the traction acting across a crack plane, $\sigma$, and the average separation distance of the crack faces, $\delta$. By definition, the relation can be obtained from a direct tension test. The form of this functional relation strongly depends on the details of the crack bridging mechanisms, fiber volume fraction, diameter, and embedment length. In most instances, the $\sigma-\delta$ relation also provides useful fracture parameters for material characterization such as composite tensile strength and fracture toughness. In addition, it could be used for numerical simulations of crack formation and propagation in structures made of the composite. Therefore, further development in microstructural design of ceramic composites and mechanical performance prediction of ceramic composite structural parts calls for a reliable testing technique for determining $\sigma-\delta$ relationships. Considering the complex fracture behavior observed in the process zone, composite optimization can only become practical when a suitable fracture testing methodology has been established based on a theoretically sound foundation in conjunction with micromechanical model development.

$\mathrm{Li}^{11}$ and $\mathrm{Li}$ et al., ${ }^{12}$ among others, have proposed a novel $J$-based fracture testing technique to determine the tensionsoftening relationship originally for characterizing the fracture behavior of concrete. The testing technique has the advantage of requiring only a simple stroke controlled loading machine and is relatively stable in comparison with direct uniaxial tensile tests. Most of the other indirect methods introduced for the measurement of the tension-softening relation to date are based on monitoring of the fracture process zone growth and crack propagation resistance curve ( $R$-curve)..$^{13}$ A review of the methods has been given by Mai. ${ }^{15}$ The determination of $R$-curves, which is the prerequisite of those testing methods, requires knowledge of the exact location of the fracture process zone tip. However, it has often been pointed out that it is difficult to identify the accurate extent of the fracture process zone in quasi-brittle materials. ${ }^{16}$ This was also true for foam glass composites tested in this study due to complicated pore structure in the matrix. The $J$-based technique overcomes this shortcoming by measuring the crack tip opening displacement rather than by monitoring the growth of the fracture process zone. It has been applied by several researchers to a number of quasi-brittle materials including concrete, 17 fiber-reinforced concrete, ${ }^{18-20}$ and rocks, ${ }^{21-23}$ in which the fracture process is primarily dominated by the formation of a fracture process zone and the contribution of the crack tip singularity is negligibly small. Further, the testing procedure has been numerically verified on the basis of the fracture process zone model. ${ }^{24.25}$ It has been shown, however, that in current advanced ceramicmatrix composites, the term of crack tip singularity cannot be neglected, and the bridging toughness is of the same order of magnitude as the crack tip singularity term. ${ }^{4-6}$

The objective of this research is to further develop the $J$-based testing procedure to explicitly account for the crack tip 
singularity while considering the bridging process zone. In this paper, the principle underlying the $J$-based technique, and the experimental and data analysis procedures, are presented. The technique is applied to fiber-reinforced foam glass composites to determine how well the testing procedure performs in practice. The test results and comparisons with those obtained by other testing methods are reported.

\section{Theoretical Basis for the $\boldsymbol{J}$-Based Technique}

This section provides the principle of the $J$-based technique, followed by a description of the testing procedure. A schematic of stress distribution around the crack tip is presented in Fig. 1(a) for a material where the crack tip singularity coexists with the fracture process zone. The development of the fracture process zone is characterized by a relationship between the stress, $\sigma$, and the crack opening displacement, $\delta$. For the closed contour shown in Fig. I(b), the $J$-integral path independent property ${ }^{26}$ requires

$$
J_{\mathrm{x}}+J_{\mathrm{b}}+J_{\text {tip }}=0
$$

The $J_{x}$ term represents the energy release rate associated with far-field loading, and contains information on the specimen geometry. The $J_{\text {tip }}$ is the crack tip singularity term. Finally. $J_{\mathrm{h}}$ is the energy consumed by the development of the fracture process zone. Thus in terms of energetics, Eq. (1) implies that the energy release rate associated with far field loading is absorbed by the creation of a unit matrix fracture surface and by fracture process zone development. Applying the $J$-integral analysis to the terms $J_{\text {up }}$ and $J_{\mathrm{b}}$ for the material with the crack tip singularity and fracture process zone, Eq. (1) can be expressed by

$$
J_{x}=\int_{0}^{\hat{\delta}_{1}} \sigma(\delta) \mathrm{d} \delta+\frac{K_{\mathrm{np}}^{2}\left(1-\nu^{2}\right)}{E}
$$

where $\delta_{1}$ is the crack opening displacement measured at the original crack tip, $\boldsymbol{K}_{\text {tip }}$ is the crack tip stress intensity factor, and $E$ and $v$ are Young's modulus and Poisson's ratio of the composite, respectively. Differentiating Eq. (2) with respect to $\delta_{1}$, the stress, $\sigma$, may then be determined from

$$
\sigma\left(\delta_{1}\right)=\frac{\partial}{\partial \delta_{1}}\left[J_{x}\left(\delta_{1}\right)-\frac{K_{\text {lip }}^{2}\left(1-v^{2}\right)}{E}\right]
$$

Thus if $J_{x}$ and $K_{\text {tip }}$ can be determined, and $\delta_{1}$ can be obtained experimentally, then the $\sigma-\delta$ relationship can be derived from Eq. (3).

In Fig. 2, the flow of the testing procedure based on the above discussion is presented. The $J$-integral value can be evaluated experimentally by conducting tests on two specimens with different crack lengths as illustrated in Fig. 3. During tests, load, $P$, load-line displacement, $\delta_{\mathrm{L}}$, and crack tip opening displacement,

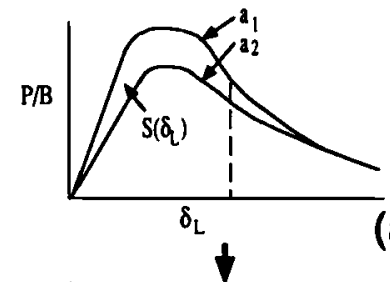

(a)
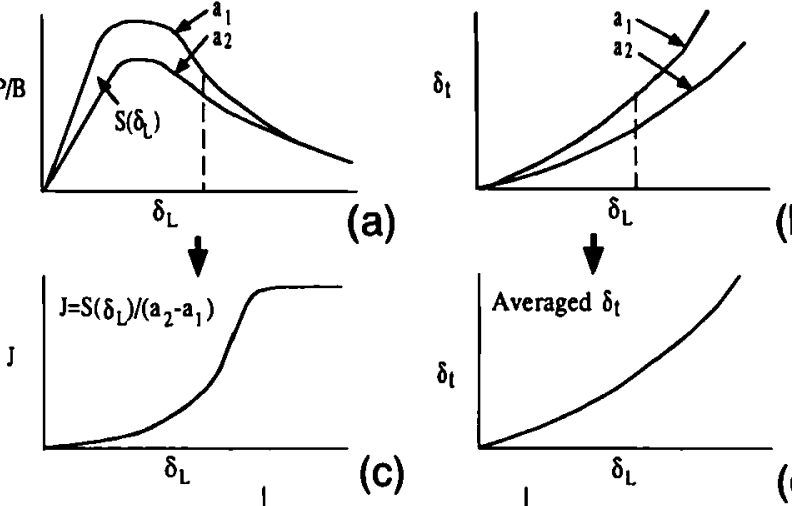

$\checkmark$

(b)
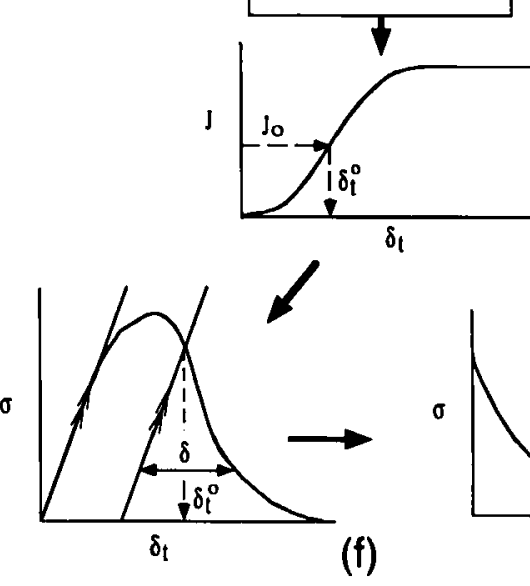

(e)

Fig. 2. Flow chart of testing procedure.

$\delta_{1}$, are measured simultaneously. The value of the $J$-integral for a given value of $\delta$, is calculated using the following equation:

$$
J_{\times}\left(\delta_{\mathrm{L}}\right)=\frac{1}{a_{2}-a_{1}} \int_{0}^{\delta_{1}}\left(\frac{P_{1}}{B_{1}}-\frac{P_{2}}{B_{2}}\right) \mathrm{d} \delta_{\mathrm{L}}=\frac{S\left(\delta_{1}\right)}{a_{2}-a_{1}}
$$

where $B$ is the specimen thickness, and $S\left(\delta_{L}\right)$ represents the area under the $P / B-\delta_{1}$ curve. The subscripts, 1 and 2 , refer to the different crack lengths, $a_{1}$ and $a_{2}$, respectively. Based on a set of $P / B-\delta_{1}$ and $\delta_{1}-\delta_{1}$, relations for each specimen with different crack lengths, the relationship between $J$ and $\delta$, is obtained as in Fig. 2(e). Figure 2(f) illustrates the $\sigma-\delta$, curve deduced from the fracture test data. Note that $\delta_{1}$ denotes the crack tip opening displacement to be experimentally obtained. In practice, in order to measure the crack tip opening displacement, relative movement between two points at opposite sides of the crack is usually monitored. ${ }^{11.12 .17} 23$ The $\sigma-\delta_{1}$ curve rises to a peak initially, then

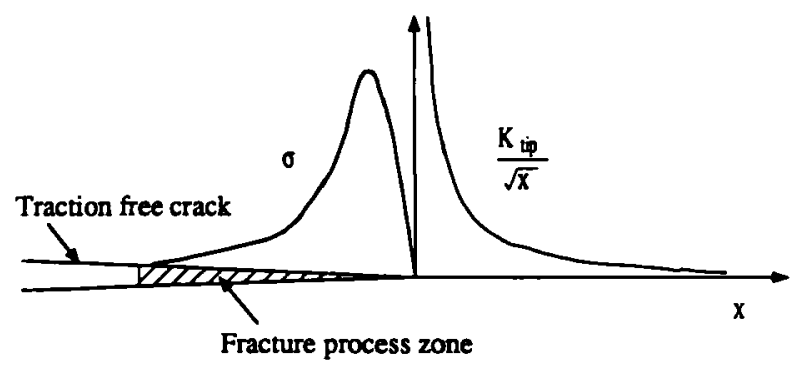

(a)

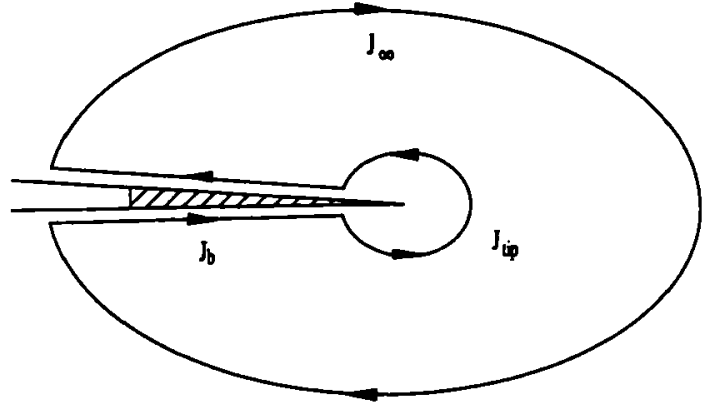

(b)

Fig. 1. Principle of $J$-based testing technique, showing (a) schematic stress distribution around the crack tip, and (b) $J$-integral contour for a material where the crack tip singularity coexists. 

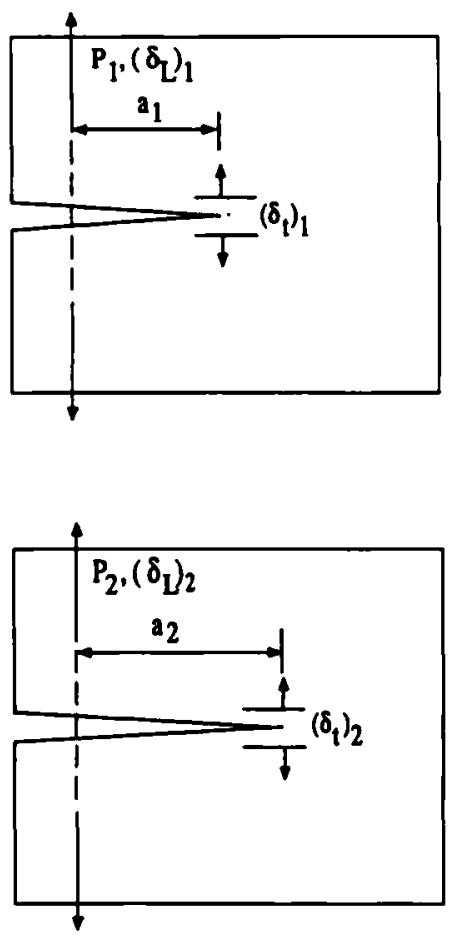

Fig. 3. Pair of specimens for $J$-based technique.

decreases with increasing $\delta_{1}$. The linearly rising portion can be interpreted as elastic deformation between the measuring points, and therefore should not be regarded as part of the $\sigma-\delta$ relation.' ' In addition, the measured value of $\delta$, contains elastic deformation due to the crack tip toughness, $J_{0}$, as well, where $J_{0}$ is the critical $J_{\text {ip }}$ for advancing the crack against the modified matrix toughness. After $J_{\text {tip }}$ reaches the $J_{0}$ value, the fracture process zone starts to grow and the stress, $\sigma$, can be calculated using Eq. (3). In principle, the determination of $J_{0}$ can be obtained from the initial value of the $R$-curve. Furthermore, when the fiber volume fraction is low, the crack tip toughness may be assumed to be equal to the matrix toughness. The deformation stage at $J_{0}$ can then be readily found in the plot of $J-\delta_{\text {, }}$ as shown in Fig. 2(e). Based on this discussion, the abovementioned deformations are subtracted from the measured $\delta$, value to extract the true $\sigma-\delta$ curve. Figure 2(g) shows the corrected $\sigma-\delta$ curve.

It should be mentioned here that a pre-peak part exists in the $\sigma-\delta$ relationship of fiber-reinforced composites, as schematically illustrated in Fig. 1. The rising part of the $\sigma-\delta$ curve is mainly associated with the debonding process of the fiber/ matrix interface. ${ }^{x .27}$ In this study, however, it was not possible to distinguish the pre-peak part from the elastic deformation due to the effect of the gage length for measuring $\delta_{i}$ and to the crack tip toughness. It must be emphasized therefore that the $\sigma-\delta$ curve to be determined by the present $J$-based technique is restricted to the post-peak (tension-softening) part of the relationship. This is true for materials with composite tensile strength higher than the maximum bridging stress provided by the fibers. A treatment of the pre-peak part in the present method will be discussed later.

\section{Experimental Procedure}

The materials used for the present investigation were foam glass composites reinforced with $\mathrm{SiC}$ (Nicalon, Nippon Carbon Co., Ltd., Chuo-ku, Tokyo, Japan) and stainless steel fibers (Tufmic fiber, Tokyo Rope Mfg. Co., Ltd., Chuo-ku, Tokyo, Japan). While the foam glass has many potential applications because of its salient features such as light weight, good thermal insulation properties, and machinability, there is a strong demand for improving the brittle fracture property of the foam glass for reliable structural applications. The dimensions and mechanical properties if the fibers used for reinforcement are given in Table I. A commercial glass powder (soda-lime glass, Central Glass Co., Ltd., Chiyoda-ku, Tokyo, Japan) with an average particle size of $16.5 \mu \mathrm{m}$ was used as the matrix material. $\mathrm{CaCO}_{3}$ was selected as a foaming agent, and the glass powder was dry-mixed with $0.15 \%$ by weight of $\mathrm{CaCO}_{3}$ using a laboratory blender. The fibers and the above glass powder mixtures were mixed using a water-based slurry method, forming a slurry. For $\mathrm{SiC}$ fibers, before mixing with the glass powder mixtures, the fibers were first dispersed in an $\mathrm{NaOH}$ solution with a magnetic stirrer. This process was necessary to achieve better uniform dispersion of the $\mathrm{SiC}$ fibers. The slurry was ultrasonically mixed, and then oven-dried at $110^{\circ} \mathrm{C}$ for $8 \mathrm{~h}$. The dried mixture was placed in a furnace, heat-treated at a rate of $10^{\circ} \mathrm{C} / \mathrm{min}$ to $800^{\circ} \mathrm{C}$, and held at $800^{\circ} \mathrm{C}$ for $10 \mathrm{~min}$. The temperature was then lowered to $550^{\circ} \mathrm{C}$ for $60 \mathrm{~min}$, and then furnace cooled to room temperature. The heat treatment at $550^{\circ} \mathrm{C}$ for 60 min was used to eliminate the residual stresses induced during the foaming process. Composites were produced at fiber volume fractions of $0.1 \%, 0.2 \%, 0.8 \%$, and $1.0 \%$ for SiC fibers and $1.6 \%, 3.3 \%$, and $5.2 \%$ for stainless steel fibers. Plain foam glass was also prepared to determine the fracture toughness of the matrix. The density of the foam glass was $0.71 \mathrm{Mg} / \mathrm{m}^{3}$. For the $\mathrm{SiC}$ fibers, the effect of fiber length on the tension-softening behavior was also examined. More detailed procedures for preparing the foam glass composites can be found elsewhere. ${ }^{2 *}$

A compact tension (CT) specimen, illustrated in Fig. 4, was used to determine tension-softening curves by means of the $J$-based technique. Side grooves were cut into the specimens using a diamond wheel saw to ensure that the crack growth remained in the median plane. Their width and depth were 4.0 and $5.0 \mathrm{~mm}$, respectively. An artificial notch with a root radius of $75 \mu \mathrm{m}$ was introduced into each specimen. Preliminary tests were conducted to check the effect of notch root acuity on the fracture toughness using the plain foam glass, where two different notch radii of 75 and $120 \mu \mathrm{m}$ were tested. No significant change in the measured fracture toughness was observed within the range of notch root radius tested. Based on these results, a root radius of $75 \mu \mathrm{m}$ was used in all specimens to simulate the sharp crack in this study.

Table I. Dimensions and Mechanical Properties of Fibers Used

\begin{tabular}{lcccc}
\hline Fiber type & $\begin{array}{c}\text { Diameter } \\
(\mu \mathrm{m})\end{array}$ & $\begin{array}{c}\text { Density } \\
\left(\mathrm{Mg} / \mathrm{m}^{3}\right)\end{array}$ & $\begin{array}{c}\text { Young s modulus } \\
(\mathrm{GPa})\end{array}$ & $\begin{array}{c}\text { Tensile strength } \\
(\mathrm{GPa})\end{array}$ \\
\hline SiC & 14 & 2.6 & 190 & 2.8 \\
SUS 430 & 50 & 8.1 & 200 & 0.52 \\
\hline
\end{tabular}
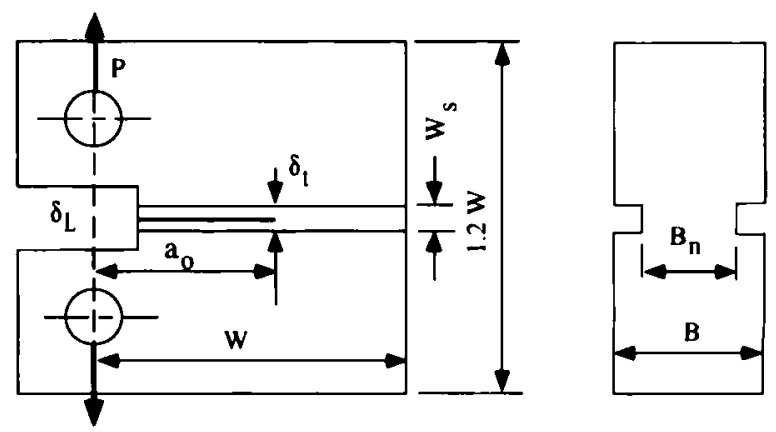

Specimen dimensions: $W=40 \mathrm{~mm}, a_{0}=17.2-25.0 \mathrm{~mm}, B=20 \mathrm{~mm}$ $B_{n}=10 \mathrm{~mm} . W_{s}=4.0 \mathrm{~mm}$

Fig. 4. Compact tension specimen used. 
The CT specimens were loaded to failure using a screwdriven testing machine. The displacement rate at the notch tip was typically $0.1 \mu \mathrm{m} / \mathrm{s}$. Load, $P$, load-line displacement, $\delta_{1}$, and crack tip opening displacement, $\delta_{t}$, were recorded continuously up to complete fracture during the tests. The $\delta_{\mathrm{L}}$ and $\delta_{\text {, }}$ were measured by double-cantilever clip-in displacement gages (clip gages) which were prepared in accordance with the ASTM Standard Test Method for Plane-Strain Fracture Toughness of Metallic Materials (E399). The resolution of the clip gages used was approximately $1 \mu \mathrm{m}$, which was typically less than $2 \%$ of the displacement range encountered in the tests. To measure the $\delta_{1}$, a pair of L-shaped knife edges were glued on side surfaces of the groove at the prenotch tip, ${ }^{21}$ as illustrated in Fig. 5. The relative displacement between the two knife edges was measured on both specimen sides using the clip gages, and the two displacement values were averaged. The gage length for measuring the $\delta$, was $4.0 \mathrm{~mm}$, and the distance between the two knife edges was $2.6 \mathrm{~mm}$. The number of specimens tested in this study is shown in Table II. Four specimens of plain foam glass were used to determine the matrix toughness.

In the calculation of the $J$-integral value the specimen thickness, $B$, in Eq. (4) was replaced by the net thickness, $B_{n}$. As described later, to cvaluate the crack tip toughness it is necessary to determine Young's modulus of the composites as well as the matrix. For this purpose, a simple compliance method ${ }^{29}$ was employed for convenience without carrying out uniaxial tensile tests. It has been shown that the effective Young's modulus $\left(=E /\left(1-v^{2}\right)\right)$ can be determined from the initial elastic slope of the load-displacement record for a fracture toughness specimen with the dimensionless specimen compliance derived from the elasticity theory. Prior to fracture testing the specimen was cyclically loaded within the linear elastic regime, and the
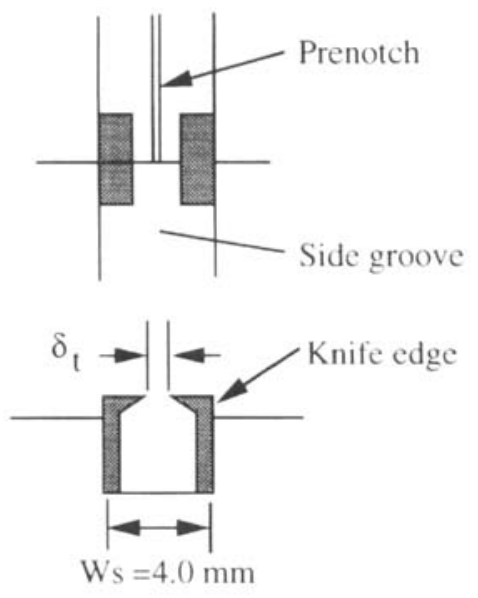

Fig. 5. Schematic of crack tip displacement measuring method.

Table II. Testing Matrix and Summary of $J$-Based Test Results

\begin{tabular}{|c|c|c|c|c|c|c|}
\hline \multicolumn{2}{|c|}{ Fiber } & \multirow{2}{*}{$\begin{array}{l}\text { No. of } \\
\text { tests }\end{array}$} & \multirow{2}{*}{$\underset{(\mathrm{GPa})}{E}$} & \multirow{2}{*}{$\begin{array}{l}\text { Deduced tensile } \\
\text { strength } \\
\text { (MPa) }\end{array}$} & \multirow{2}{*}{$(\mathrm{N} / \mathrm{m})$} & \multirow{2}{*}{$\begin{array}{c}K_{4} \\
\left(\mathrm{MPa} \cdot \mathrm{m}^{\prime}\right.\end{array}$} \\
\hline$L_{1}(\mathrm{~mm})$ & $V(\%)$ & & & & & \\
\hline \multicolumn{7}{|c|}{ SiC tiber composites } \\
\hline 3 & 1.0 & $6(2 *)$ & 7.6 & 1.4 & 61.6 & 0.70 \\
\hline 6 & 1.0 & $6(2)$ & 8.0 & 1.9 & 147.5 & 1.11 \\
\hline 13 & 0.1 & $6(3)$ & 7.7 & 1.7 & 3.5 & 0.17 \\
\hline 13 & 0.2 & $6(2)$ & 7.7 & 1.7 & 14.8 & 0.35 \\
\hline 13 & 0.8 & $4(2)$ & 8.0 & 1.9 & 210.0 & 1.32 \\
\hline 13 & 1.0 & $6(2)$ & 8.2 & 2.0 & 241.8 & 1.44 \\
\hline \multicolumn{7}{|c|}{ SUS fiber composites } \\
\hline 2 & 1.6 & $4(2)$ & 8.4 & 1.2 & 5.7 & 0.22 \\
\hline 2 & 3.3 & $4(2)$ & 8.6 & 2.0 & 98.9 & 0.94 \\
\hline 2 & 5.2 & $4(2)$ & 8.6 & 2.1 & 108.6 & 0.99 \\
\hline
\end{tabular}

*Number of specimens used for $R$-curve measurements. load-displacement curve was recorded. The inverse slope of the load-displacement curve (initial specimen compliance) was used to determine the effective Young's modulus. Assuming the effect of the fiber addition on Poisson's ratio is negligibly small, Young's modulus values of the composites were then computed from the effective Young's modulus data. Poisson's ratio was taken to be 0.2 in the calculations. ${ }^{30}$ The dimensionless specimen compliance for the CT specimen was taken from Newman's boundary collocation analysis." Futhermore, the numerical analysis of Shih et $a l^{32}$ was used to account for the effect of the side groove on the specimen compliance. If $\boldsymbol{B}_{\mathrm{eft}}$ is the effective specimen thickness, then

$$
B_{\mathrm{cff}}=\frac{B-\left(B-B_{\mathrm{n}}\right)^{2}}{B}
$$

\section{Results and Discussion}

Examples of load vs load-line displacement records $\left(P-\delta_{L}\right)$ are shown in Fig. 6. Experimental data obtained from identical notch length are selected for comparison. The plain foam glass used as the matrix exhibited brittle fracture behavior. allowing the fracture toughness to be determined using the linear elastic fracture mechanics approach. The matrix fracture toughness was computed from the maximum load and notch length using the formula of the stress intensity factor. ${ }^{31}$ Likewise in the determination of Young's modulus the effective specimen thickness was used. The average value of the matrix toughness is $0.95 \mathrm{MPa} \cdot \mathrm{m}^{1 / 2}$. As evident in Fig. 6, the incorporation of a relatively low volume fraction of the fibers provides improved fracture properties of the foam glass.

The newly derived extended $J$-based technique is applied to the load-displacement data of the fiber-reinforced foam glass composites. The critical $J_{\text {tip }}$ value, $J_{0}$, may be calculated from the critical stress intensity factor to determine the crack tip opening displacement, $\delta_{1}^{0}$ (see Fig. 2(e)). Following Marshall et al. ${ }^{8}$ since the stress intensity factor scales directly with stress, the crack tip toughness can be calculated by

$$
K_{0}=\left(\frac{E}{E_{\mathrm{m}}}\right) K_{\mathrm{m}}
$$

$E_{\mathrm{m}}$ and $K_{\mathrm{m}}$ are the matrix Young's modulus and fracture toughness, respectively. The compliance method showed that the average value of $E_{\mathrm{m}}$ is $8.1 \mathrm{GPa}$, and the composite Young's

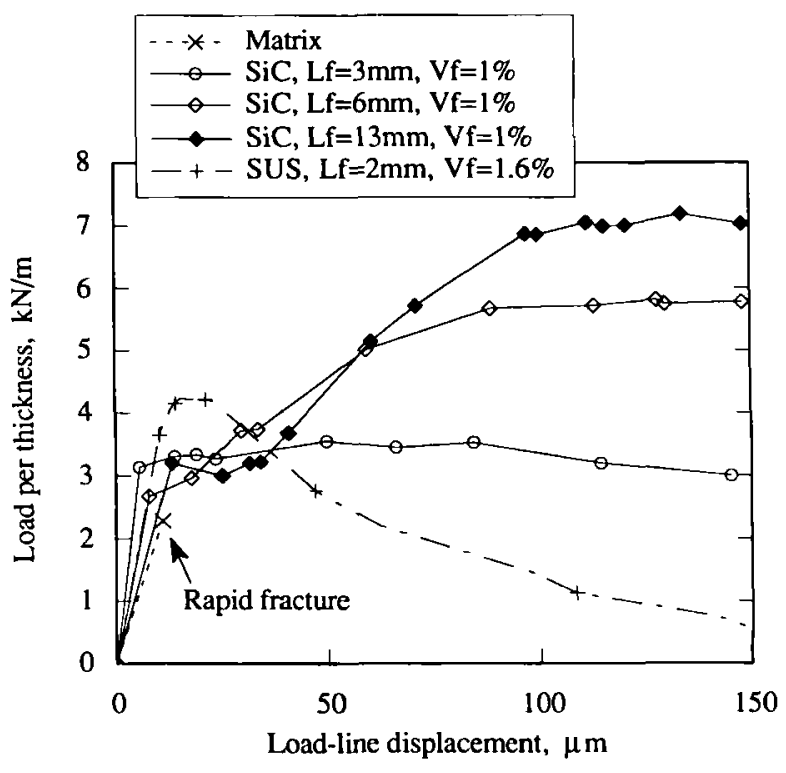

Fig. 6. Load vs load-line displacement curves for matrix. SiC tiber. and stainless steel fiber composites. 
modulus differs by less than $5 \%$ from that of the matrix within the fiber volume fractions used in this study. Based on these results, the matrix elastic moduli were taken to compute $J_{0}$, using the equation $J_{0}=K_{0}^{2}\left(1-\nu_{\mathrm{m}}^{2}\right) / E_{\mathrm{m}}$. Typical $P-\delta_{\mathrm{L}}$ curves for different notch lengths are shown in Fig. 7 for a SiC fiber composite. It is seen that the $P-\delta_{1}$ curve for the long notch length joins with that for the short notch length approximately at the load-line displacement of $500 \mu \mathrm{m}$, indicating that the traction free crack starts to grow at the deformation level. Using the date analysis procedure shown in Fig. 2, tension-softening curves are deduced from sets of $P-\delta_{1}$ and $\delta_{1}-\delta_{1}$ curves. Examples of tension-softening curves obtained are shown in Fig. 8 for $\mathrm{SiC}$ fiber and stainless steel fiber composites. The $\sigma-\delta$ curve in the figure gives the averaged tension-softening relation. The derivation of individual raw data from the best fit was typically less than $15 \%$.

In the following, we examine the validity of the deduced tension-softening curves. Fracture surfaces were examined using a scanning electron microscope, and representative examples are shown in Figs. 9 and 10 for a $\mathrm{SiC}$ and stainless steel fiber composite, respectively. As shown in Fig. 9(a), some fibers are seen bridging across crack faces in the $\mathrm{SiC}$ fiber composites. Fibers were observed protruding above the fracture surface (Fig. 9(b)). However, in all cases the extent of fiber pullout was limited to a length less than approximately $10 \%$ to $30 \%$ of the original fiber length. This observation suggests that the lengths of $\mathrm{SiC}$ fibers used are much greater than the critical fiber length, indicating that fibers with long embedded length have ruptured. In contrast, for stainless steel fibers no fiber pullout was observed. It appears that the predominant contribution to toughness is plas-

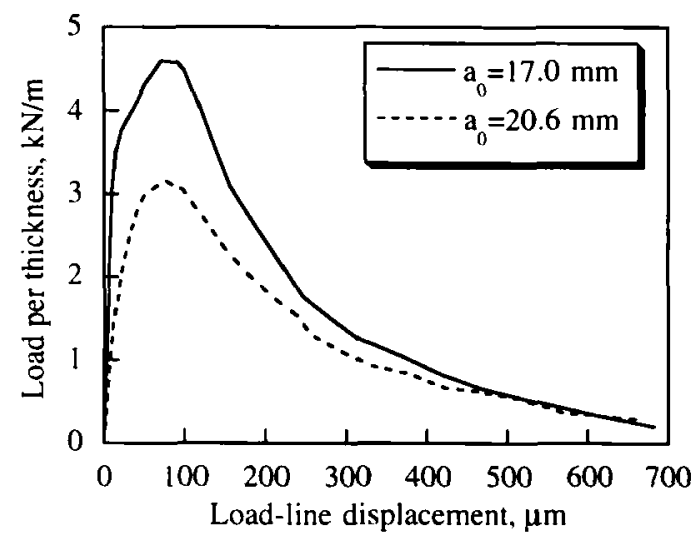

Fig. 7. Examples of load vs load-line displacement curves for different prenotch lengths, showing results of SiC fiber composite $\left(L_{\mathrm{t}}=3\right.$ inm. $V_{1}=1 \%$ )

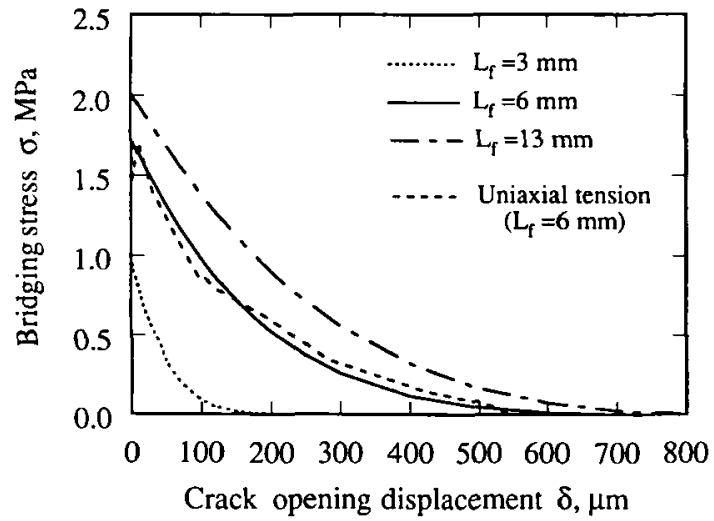

(a) tic work expended in the ductile rupture of the fibers stretched between the crack surfaces, as exemplified in Fig. 10. From the observation of fracture surfaces, the fiber pullout is considered to be a primary source of bridging force acting across the matrix crack in the SiC fiber composites. Then, the critical crack opening displacement, $\delta_{c}$, at which the fiber bridging force becomes zero, is expected to coincide with the maximum length of fiber pullout. The histograms of Fig. 11 give the distribution of fiber pullout lengths measured under a scanning electron microscope. The critical crack opening displacements obtained from the $J$-based technique are indicated by arrows. It is observed that the $\delta_{c}$ values are close to the longest pullout length. The correspondence between the results deduced from the $J$-based technique and microscopic fracture process provides confidence in our testing procedure.

Next, the fracture data obtained from the tension-softening curves are compared with those from the fracture energy method and crack propagation resistance curve ( $R$-curve) approach. The critical total $J$-value, $J_{c}$, can be obtained as the sum of the bridging toughness, $J_{\mathrm{b}}$, and the matrix toughness. $J_{t r}$. The $J_{\mathrm{b}}$ can be evaluated from the area under the tension-softening curve. Another conventional method for measuring fracture toughness in quasi-brittle materials may be the RILEM-recommended fracture energy method. ${ }^{33}$ The evaluation procedure in the fracture energy method is based on the same planar process zone model as in the $J$-based technique, and determines the fracture energy $G_{\mathrm{F}}$ by measuring load-load-line displacement curves. In principle, $G_{\mathrm{F}}$ is thus equivalent to $J_{\mathrm{c}} . G_{\mathrm{F}}$ is defined as

$$
G_{\mathrm{F}}=\frac{A}{B_{\mathrm{n}}\left(W-a_{0}\right)}
$$

where $A$ is the total area under the load-load-line displacement curve and $a_{0}$ is the prenotch length. The $J_{c}$ values are plotted against $G_{\mathrm{F}}$ values obtained using Eq. (7) in Fig.12, where the values of $G_{F}$ are obtained from a pair of specimens used for the $J$-based testing. There is correspondence between the results from the two testing methods. To look at the crack extension behavior in the composites, the unloading compliance measurements were concurrently carried out in some $J$-based tests, and $K$-resistance curves were constructed. Taking into account observed significant nonlinear deformation during unloadingreloading cycles, the test data were analyzed following the nonlinearity correction procedure which was originally proposed by Baker $^{34}$ and then adopted in the ISRM-suggested methods for determining the fracture toughness of rocks. ${ }^{35}$ The $K$-resistance curve is corrected for the nonlinear defomation behavior using the following equation:

$$
K=\sqrt{\frac{1+p}{1-p}} K_{\text {। }}
$$

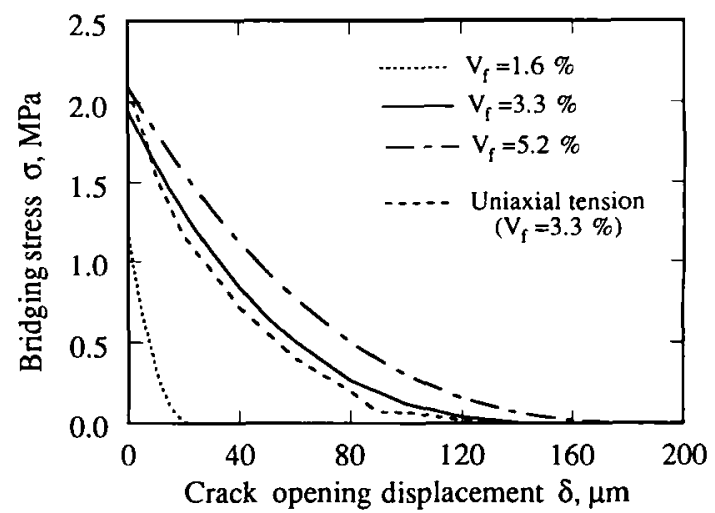

(b)

Fig. 8. Deduced tension-softening curves for (a) SiC fiber composites, and (b) stainless steel fiber composites. 


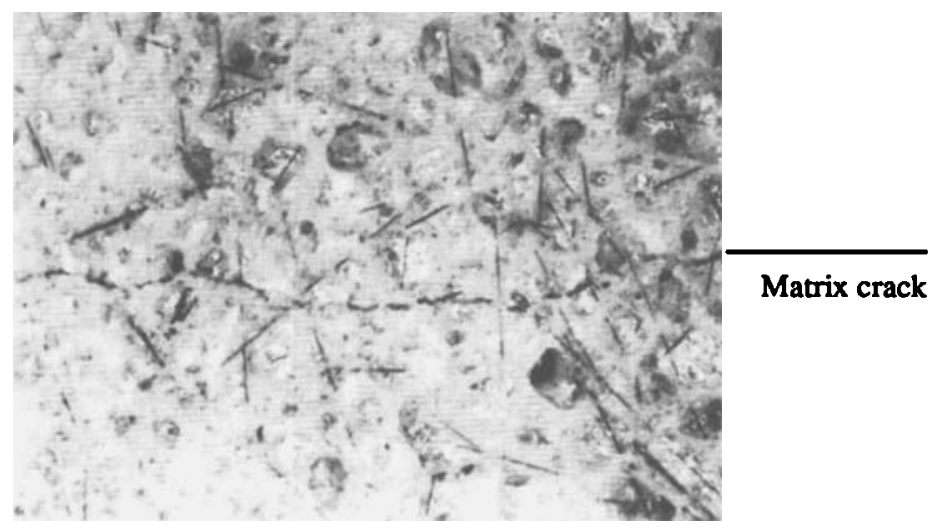

(a)

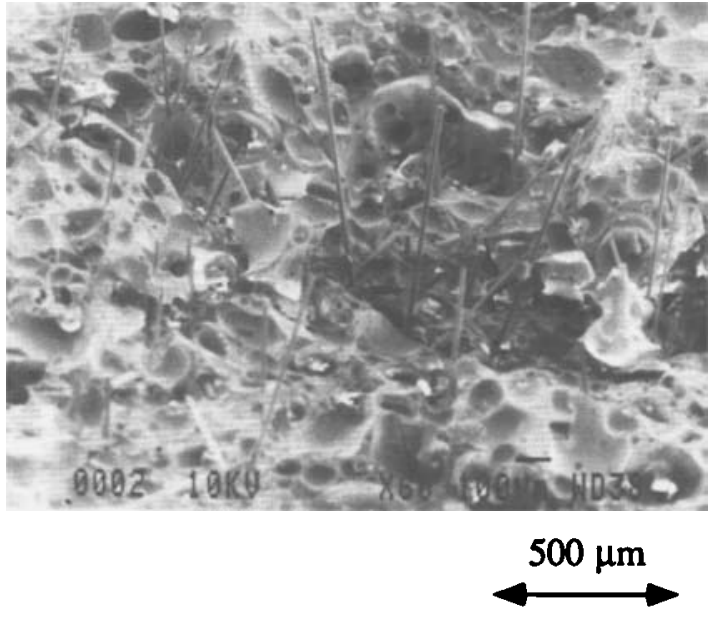

(b)

Fig. 9. SEM micrographs of fracture process for a SiC fiber composite, showing (a) fiber-matrix interactions, and (b) fiber pullout.

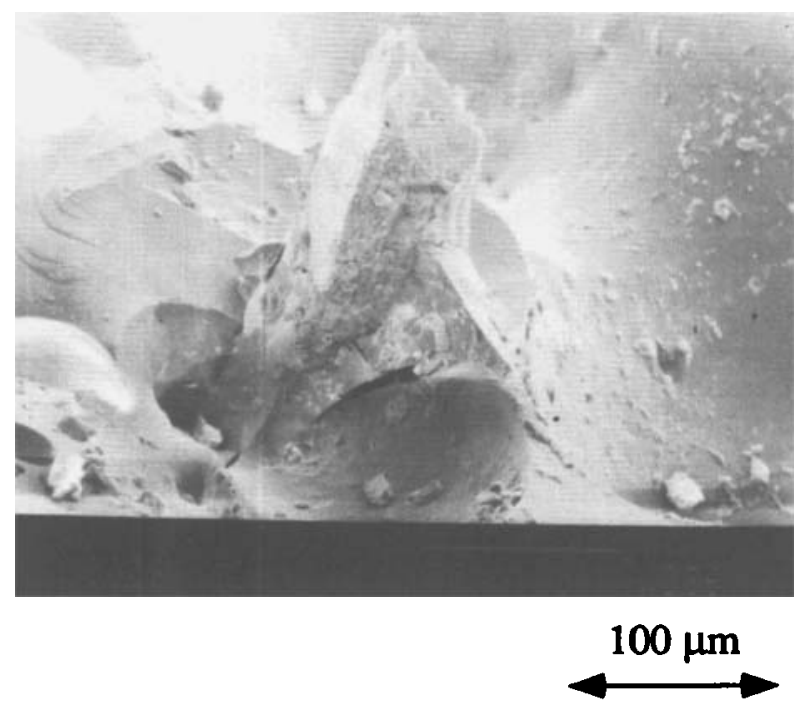

Fig. 10. SEM micrograph of stainless steel fiber showing the ductile rupture.

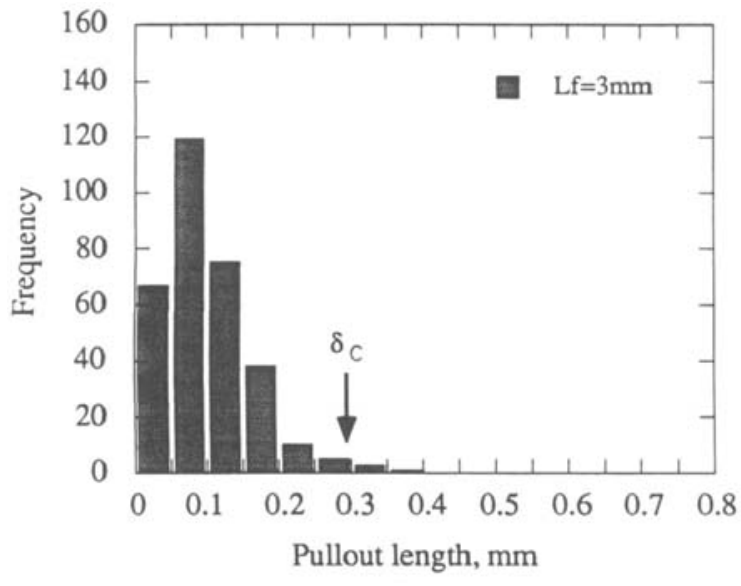

(a)

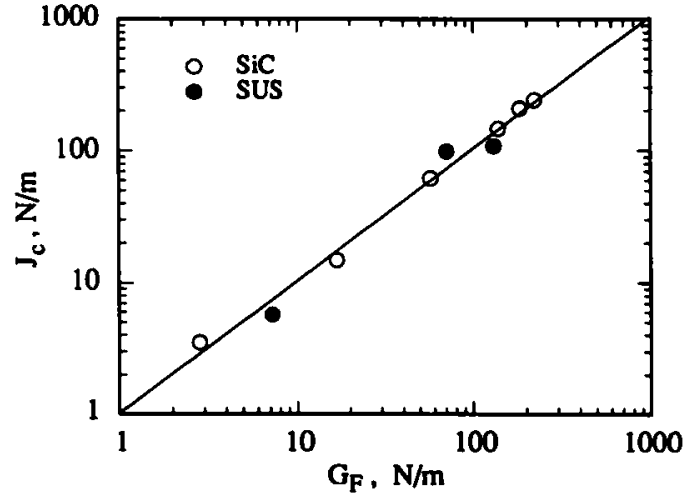

Fig. 12. Comparison between $J_{\mathrm{c}}$ and $G_{\mathrm{F}}$.

$K_{\mathrm{L}}$ is the linear elastic stress intensity factor calculated from load and corresponding crack length, $p$ is the nonlinear correction factor determined from the load-load-line displacement curve with unloading and reloading cycles. The $K_{\mathrm{L}}$ and $K^{\mathrm{R}}$ to be determined below are calculated based on the effective crack length obtained by the unloading compliance method. The unloading compliances after crack propagation are inevitably

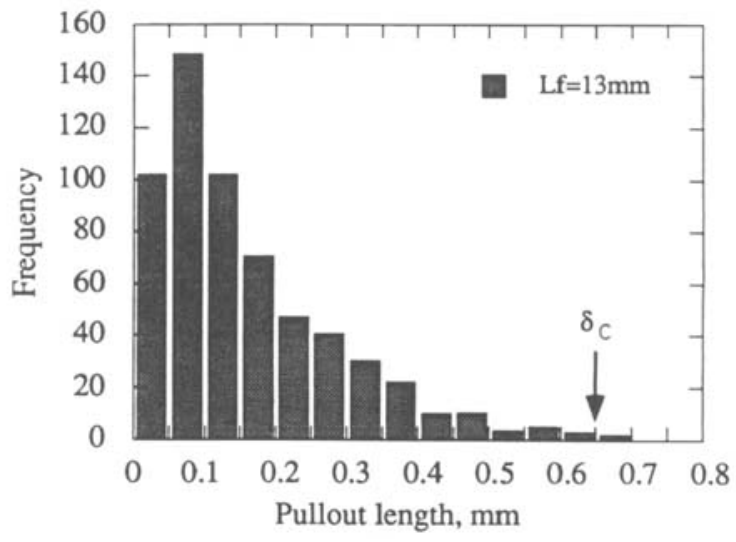

(b)

Fig. 11. Histograms for distribution of fiber pullout length for (a) original fiber length $L_{1}=3 \mathrm{~mm}$ and (b) $L_{\mathrm{r}}=13 \mathrm{~mm}$. 
reduced by the bridging stress closing up the crack. Thus the effective crack length determined by the unloading compliance method should be regarded as a lower bound estimate of the true value. Detailed procedures for determining $p$ can be found in the ISRM-suggested methods. ${ }^{39}$ Figure 13 illustrates a $K$-resistance curve for a SiC-fiber-reinforced composite. For comparison. the curve based on the linear elastic analysis is also given. It is seen that the initiation toughness of the composite is close to the matrix toughness. The observation may support the use of $R$-curves to determine the crack tip toughness of composites. The interpretation of the initiation toughness will be discussed later. Crack propagation resistance initially increases because of fiber bridging, and then levels off for a longer crack propagation stage, indicating full development of the fiber bridging zone. At the saturated stage, the increase of crack propagation resistance over the matrix toughness should correspond to the total energy consumed by fiber bridging. The comparison is made in Fig. 14. $K_{\mathrm{b}}$ is the converted bridging toughness computed using the following equation: ${ }^{15}$

$$
K_{\mathrm{b}}=\sqrt{K_{0}^{2}+E J_{\mathrm{b}}}-K_{0}
$$

Thus, $K_{\mathrm{b}}$ is based on the total crack length, which is the sum of the traction free crack length and the fracture process zone size. $\Delta K^{\mathrm{R}}$ is the difference of the saturated toughness and the matrix toughness as shown in Fig. 13. Again, there is general correspondence between $K_{\mathrm{b}}$ and $\Delta K^{\mathrm{R}}$, although this should be taken to be only a qualitative comparison due to the effect of the bridging stress on the measurement of the crack length based on

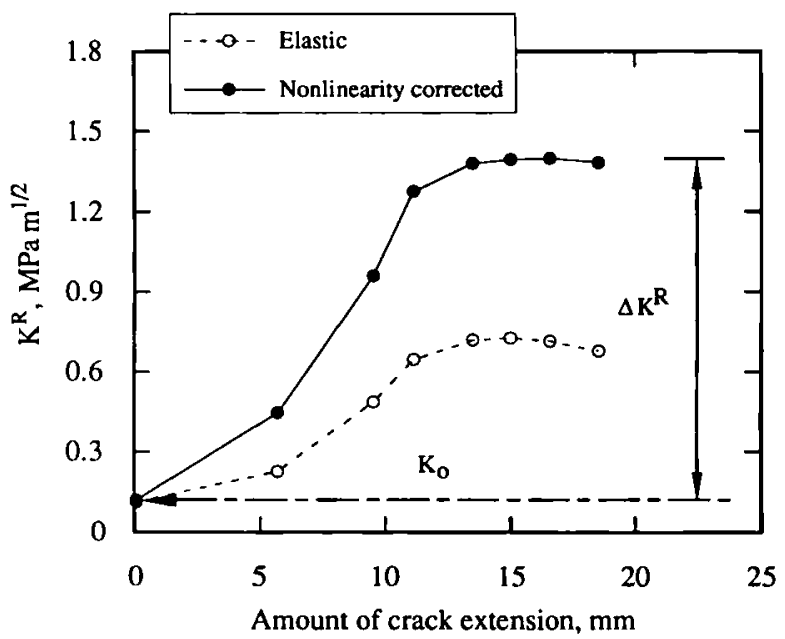

Fig. 13. Example of $K$-resistance curve.

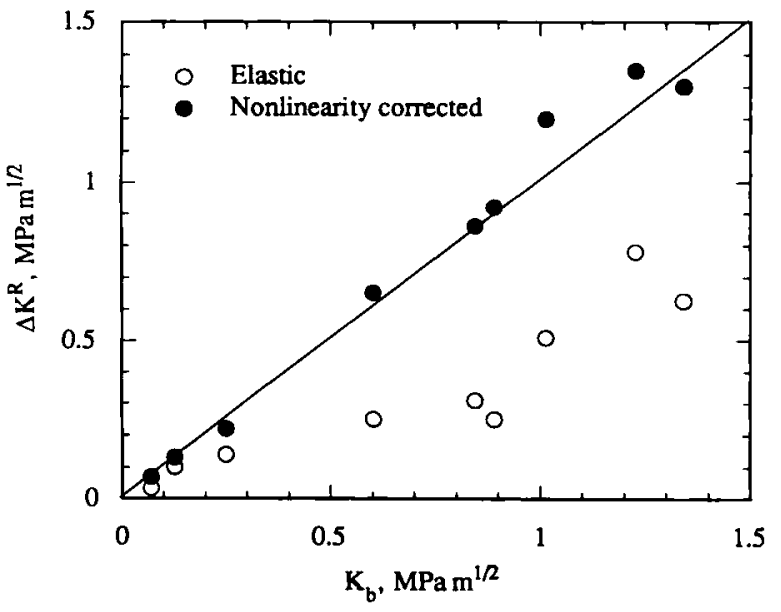

Fig. 14. Comparison between $K_{\mathrm{b}}$ and $\Delta K^{\mathrm{R}}$. the unloading compliance method. It may be useful to examine the ratio of bridging toughness $K_{\mathrm{b}}$ to crack tip toughness $K_{0}$ in order to characterize the composites tested in this study. The calculated values of $K_{\mathrm{h}} / K_{0}$ range between 0.7 and 22.2. This calculation indicates that the foam glass composites used indeed cover a material in which the crack tip toughness is comparable to the bridging toughness in the fracture process zone.

Table III illustrates the typical range of the $K_{\mathrm{b}} / K_{0}$ ratio for fiber-reinforced ceramic composites. The ratios are calculated based on published data of matrix and composite fracture toughness which have been determined either by means of fracture toughness tests on precracked specimens or using indentation technique..$^{6.36 .37}$ The crack tip toughness is taken from the initiation toughness measured using an $R$-curve approach, for the lithium aluminosilicate (LAS) glass, and aluminum-fiberreinforced $\mathrm{Al}_{2} \mathrm{O}_{3}$ composites. For the other composites, the crack tip toughness has been estimated from the matrix toughness, and composite and matrix Young 's moduli using Eq. (6), where the rule of mixture, i.e., $E=E_{\mathrm{m}}\left(1-V_{\mathrm{f}}\right)+E_{\mathrm{f}} V_{\mathrm{l}}$ with $E_{\mathrm{l}}$ as the fiber modulus, has been used to calculate the composite modulus. $K_{\mathrm{b}}$ is estimated as the difference between the composite toughness and the crack tip toughness $K_{0}$. It is noted that most of the data reported in the literature fall in the range of the foam glass composites tested in this investigation. The rule of mixture used to estimate the composite modulus is known to give the upper limit for random short-fiber-reinforced composites. In addition, Miyajima and Sakai ${ }^{38}$ have reported an experimental study of crack tip fracture toughness, where fracture toughness tests were conducted on a carbon/carbon composite reinforced with uniaxially aligned fibers. It has been shown that the experimentally determined crack tip toughness value was lower than that predicted by Eq. (6). Hence, the $K_{\mathrm{h}} / K_{\text {u }}$ ratios calculated using the estimated $K_{0}$ values may be considered to be a lower limit. Furthermore, it is revealed that some monolithic ceramics such as coarse-grained alumina also exhibit $R$-curve behavior, ${ }^{34} 44$ which is consistent with the tensionsoftening model. ${ }^{+3}$ Extensive microscopy observations have shown that the mechanism responsible for $R$-curve behavior is matrix grain bridging due to unbroken ligaments behind the advancing crack tip. ${ }^{4,42}$ The $K_{\mathrm{h}} / K_{0}$ ratios obtained for selected monolithic ceramics are also included in Table III. The $K_{11}$ value is taken from the initial value of $R$-curves, and thus should be interpreted as crack initiation toughness. It is seen that monolithic ceramics may be classified in the same category as current short-fiber-reinforced ceramic composites based on this characterization. This observation suggests that the $J$-based testing procedure may be used to determine the tension-softening relationship of current monolithic ceramics as well as fiberreinforced ceramic-matrix-based composites.

$R$-curve approaches have been frequently used by a number of investigators in order to characterize the toughening behavior of fiber-reinforced ceramic-matrix composites. In most fiberreinforced ceramic composites the increased energy absorption is due to the growth of the process zone. The details of process zone growth is related to the shape of the $\sigma-\delta$ curve, and also influenced by the stress field surrounding the process zone. ${ }^{45}$ This implies that with different loading configurations, and specimen geometries and dimensions, the details of the shape of

Table III. Bridging Toughness Ratio, $K_{\mathrm{b}} / K_{\mathbf{0}}$

\begin{tabular}{|c|c|c|c|c|c|}
\hline Matrix & Fiber $\left(V_{1}\right)$ & ${ }_{\left(\mathrm{G} \mathrm{Pa}_{\mathrm{a}}\right)}^{E_{1}}$ & $\begin{array}{c}K_{11} \\
\left(\mathrm{MPa} \cdot \mathrm{m}^{1 \cdot 2}\right)\end{array}$ & $K_{\mathrm{n}} / K_{\mathrm{u}}$ & Ref. \\
\hline \multicolumn{6}{|c|}{ Fiber-reinforced ceramic composites } \\
\hline $\begin{array}{l}\mathrm{Al}_{2} \mathrm{O}_{3} \\
\mathrm{Si}_{3} \mathrm{~N}_{4} \\
\mathrm{LAS}_{4} \text { glass } \\
\mathrm{Al}_{2} \mathrm{O}_{3}\end{array}$ & $\begin{array}{r}\mathrm{SiC}(30 \%) \\
\mathrm{SiC}(20 \%) \\
\mathrm{SiC}(22 \%) \\
\mathrm{Al}(23 \%)\end{array}$ & $\begin{array}{l}400 \\
320\end{array}$ & $\begin{array}{l}3.5 \\
4.6 \\
5.5 \\
3.0\end{array}$ & $\begin{array}{l}0.8-1.3 \\
0.5-1.1 \\
3.4 \\
2.3\end{array}$ & $\begin{array}{r}6 \\
36 \\
37 \\
37\end{array}$ \\
\hline \multicolumn{6}{|c|}{ Monolithic ceramics } \\
\hline $\begin{array}{l}\mathrm{Al}_{2} \mathrm{O}_{3} \\
\text { Graphite }\end{array}$ & & $\begin{array}{r}400 \\
9\end{array}$ & $\begin{array}{l}2.0-3.3 \\
0.8\end{array}$ & $\begin{array}{l}0.9-2.0 \\
0.6\end{array}$ & $\begin{array}{l}39-43 \\
44\end{array}$ \\
\hline
\end{tabular}


the $R$-curve would also be different. Indeed, it has been recently shown that the $R$-curve obtained by testing a small specimen depends on the specimen dimensions such as crack length and specimen width, and the apparent fracture resistance increases as the specimen size decreases. ${ }^{\text {th }}$ Based on this, Zok and Hom ${ }^{\text {th }}$ have pointed out that the $R$-curve measured on a small specimen overestimates the true behavior unless the bridging zone length is sufficiently small compared with the crack length or the specimen width, and then have indicated the importance of the analysis of the large-scale bridging. At developmental stages of new composite materials, it is quite common that only small specimens are available for mechanical testing and smallscale bridging conditions are hardly satisfied in some composites. Thus it is extremely useful to have a small specimen method for evaluating the true toughening behavior for efficient material developments. In this regard, a method has been proposed for predicting the toughness enhancement under smallscale bridging conditions using $R$-curve measurements from subsized specimens. ${ }^{\text {th }}$ The $J$-integral approach used in the present testing technique requires no assumption of small-scale bridging conditions, and it is expected therefore that the specimen size should not affect the measured $\sigma-\delta$ relation and the fracture toughness $J_{c}$. Furthermore, once the $\sigma-\delta$ relation is determined, it can be used to predict the $R$-curve behavior in a given structural component using, for example, a finite element scheme. Therefore, the $J$-based method is expected to provide a basis for the analysis of large-scale bridging.

Finally, it should be emphasized again that the $\sigma-\delta$ curves deduced by the extended $J$-based technique should be interpreted as the post-peak branch of the complete relationship. It has been shown that intact fiber bridging, associated with the prepeak part of the $\sigma-\delta$ relationship, exists over only a very short distance behind the crack tip, typically on the order of several micrometers for fiber-reinforced composites. ${ }^{4.17}$ The fiber bridging zone length is sufficiently small compared with normal laboratory specimen size, and small-scale bridging conditions would therefore be satisfied in such a composite whose toughness is dominated by only the intact fiber bridging. In this case, the linear elastic fracture mechanics approach can be used to characterize the composite toughness, as adopted in the literature. $^{2 .+5}$ The above discussion suggests that for fiber-reinforced ceramic composites, the fracture energy dissipated upon the fiber debonding process could be lumped into an "effective" crack tip toughness $K_{0}$, and then the process zone could be approximated by only the tension-softening part of the $\sigma-\delta$ relationship. It has been shown that the fiber debonding process produces a much steeper rising $R$-curve within a very small amount of crack growth than the subsequent fiber pullout stage. ${ }^{37.47}$ The crack resistance at the bend over point may be taken as an estimate of the effective $K_{0}$ to incorporate the effect of fiber debonding: The correspondence between the matrix toughness and initiation toughness, observed for the foam glass composites, may be due to the low fiber volume fractions used in this study. The fracture behavior of the composite will then be well predicted by the effective $K_{0}$ and the tension-softening relationship. Our recent preliminary tests conducted on a dogbone type of uniaxial tensile specimens have also shown that the fracture energy of the foam glass composites is dominated by the post-peak behavior: A servo-controlled testing machine was used to perform stable uniaxial tensile tests and the displacement monitored by a linear variable differential transducer attached to the reduced cross section (gage length $=7 \mathrm{~mm}$ ) was used as a feedback signal. A linear elastic deformation behavior was observed up to a peak, followed by a tension-softening branch. An example of the post-peak part obtained from the uniaxial tensile tests is compared with that determined by means of the $J$-based method in Fig. 8. The comparison may provide experimental justification of the shape of the $\sigma-\delta$ curve derived by the $J$-based technique. It is well accepted that fiber pullout is one of the most effective mechanisms to significantly increase the toughness for fiber-reinforced ceramic composites. An insight into the effect of fiber pullout has been provided by
Zok et al. ${ }^{37}$ who tested three-point bending specimens of LAS glass-ceramic composites reinforced with continuous $\mathrm{SiC}$ fibers, simulated numerically the crack growth in the specimens based on the micromechanical model, ${ }^{4 \times}$ and then correlated the experimental and theoretical results. Several heat treatments of the composite have been conducted to modify the matrix/fiber interface and to activate fiber sliding. It is concluded that the enhanced toughness of the LAS/SiC composites with a modified interface is derived mainly from frictional dissipation upon the pullout of tibers that fracture in the crack wake remote from the crack plane. The same conclusion has been drawn for a $\mathrm{SiC}$ composite reinforced with continuous carbon fibers. ${ }^{47}$ It may be possible, therefore, to apply the current method to the evaluation of those modern fiber-reinforced composites in which the toughness is primarily imparted by the fiber pullout mechanism. However, the pre-peak part of the $\sigma-\delta$ relationship has been demonstrated to play an important role in governing the magnitude of the first crack strength, and the presence or absence of multiple cracking behavior. ${ }^{x+4}$ Further development of experimental technique and data analysis procedure is required to evaluate the complete $\sigma-\delta$ relation. Computer simulations are currently in progress in order to verify numerically the $J$-based testing procedure proposed in this study.

\section{Concluding Remarks}

The $J$-based fracture testing technique has been newly extended in order to cover advanced composites which have matrix toughness comparable to bridging toughness induced by fibers in the fracture process zone. On the basis of the $J$-integral analysis of the fracture process zone with crack tip singularity, a testing procedure has been developed to determine the bridging stress-crack opening displacement relation $(\sigma-\delta)$. This new technique has been applied to the experimental results of fracture tests conducted on foam glass composites reinforced with $\mathrm{SiC}$ and stainless steel fibers. The primary fiber bridging mechanism identified for the process zone development is fiber pullout for SiC fibers, and ductile stretching for stainless steel fibers, respectively. Therefore, the enhanced toughness of composites is mainly associated with tension-softening behavior, i.e., the post-peak part of the $\sigma-\delta$ curve. The fracture properties deduced from the $\sigma-\delta$ relationships have been compared with other conventional methods and good agreement has been obtained, supporting the validity of the new $/ /$-based fracture testing method.

One deficiency of the $J$-based testing procedure presented in this paper is the fact that it can only evaluate the post-peak part of the $\sigma-\delta$ relationship. The pre-peak part has been shown to play an important role, for example, in the design of the pseudostrain hardening property induced by multiple cracking. Further study is needed to determine the pre-peak part of the $\sigma-\delta$ relationship.

Acknowledgments: T. H. would like to thank S. Okuda and S. Ohmi for useful discussions and their help in carrying out the experiments reported in this paper.

\section{References}

'P. F. Becher. T. N. Tiegs. J. C. Ogle. and W. H. Warwick, "Toughening of Ceramics by Whisker Reinforcement": pp 61-73 in Fracture Mechanics of Ceramics. Vol. 7. Composites, Impact. Statistics, and High-Temperature Phe' nomena. Edited by R. C. Bradt. D. P. H. Hasselman. A. G. Evans, and F. F Lange. Plenum Press, New York. 1986.

M. Ruhle. B. J. Dalgleish. and A. G. Evans, "On the Toughening of Ceramic by Whiskers." Sir. Merall., 21, 681-86 (1987).

A. G. Evans, "Perspective on the Developinent of High-Toughness Ceram ics,"J. Am. Ceresm. Soc., 73 |2|187-206 (1990).

${ }^{+}$P. B. Becher, C. H. Hsueh. P. Angelini. and T. N. Tiegs. "Toughening Behavior in Whisker-Reinforced Ceramic Matrix Composiles," J. Am. Ceram. Sorc.. 71 [12] 1050-61 (1988).

'G. H. Camphell, M. Rühle, B. J. Dalgleish, and A. G. Evans, "Whisker Toughening: A Comparison Between Aluminum Oxide and Silicon Nitride Toughened with Silicon Carbide." J. Am. Ceram. Soc., 73 [3] 521-30) (1990).

"I. Homeny, W. L. Vaughn, and M. K. Ferber, "Silicon Carbide Whisker/Alumina Matrix Composites: Effect of Whisker Surface Treatment on Fracture Toughness." J. Am. Ceram. Soc.. 73 [2] $394-402$ (1990). 
'G. I. Barenblatt, "Mathematical Theory of Equilibrium of Cracks in Brittle Fracture": pp. 55-129 in Advances in Applied Mechanics, VII. Academic Press, New York, 1962.

${ }^{8}$ D. B. Marshall, B. N. Cox, and A. G. Evans, "The Mechanics of Matrix Cracking in Brittle-Matrix Fiber Composites," Acta Metall, 33 [11] 2013-21 (1985).

'L. S. Sigl, P. A. Mataga, B. J. Daigleish, R. M. McMeeking, and A. G. Evans, "On the Toughness of Brittle Materials Reinforced with a Ductile Phase," Acta Metall., 36 [4] 945-53 (1988).

"M. F. Ashby, F. J. Blunt, and M. Bannister, "Flow Characterizations of Highly Constrained Metal Wire," Acta Metall., 37 [7] 1847-57 (1989).

iv. C. Li, "Fracture Resistance Parameters for Cementitious Materials and Their Experimental Determination": Pp. 431-49 in Application of Fracture Mechanics to Cementitious Composites. Edited by S. P. Shah. Marinus Nijhoff Publishers, Dordrect, Netherlands, 1985.

${ }^{12}$ V. C. Li, C. M. Chan, and C. K. Y. Leung, "Experimental Determination of the Tension-Softening Curve in Cementitious Composites," Cem. Concr. Res., $17[3]$ 441-52 (1987)

"C.-H. Hsueh and P. F. Becher, "Evaluation of Bridging Stress from $R$-Curve Behavior for Nontransforming Ceramics," J. Am. Ceram. Soc., 71 [5] C-234 C-237 (1988).

${ }^{14}$ X.-Z. Hu and Y.-W. Mai, "General Method for Determination of CrackInterface Bridging Stresses," J. Mater. Sci., 27, 3502-10 (1992).

1"Y.-W. Mai, "Fracture and Fatigue of Non-Transformable Ceramics: The Role of Crack-Interface Bridging"; pp. 3-26 in Fracture Processes in Concrete. Rock and Ceramics. Edited by J. G. M. van Mier, J. G. Rots, and A. Bakker. E \& FN Spon, London, U.K., 1991

'6P. L. Swanson, "Tensile Fracture Resistance Mechanism in Brittle PolyCrystals, An Ultrasonic and In Situ Microscopy Investigation," J. Geophys. Res., 92, 8015-36 (1987).

"S. Teramura, N. Nomura, T. Hashida, H. Takahashi, and H. Mihashi, "Development of a Core-Based Testing Method for Determining Fracture Energy and Tension-Softening Relation of Concrete"; pp. 463-73 in Micromechanics of Failure of Quasi-brittle Materials. Edited by S. P. Shah, S. E. Swarzz, and M. L. Wang. Elsevier Applied Science, London, U.K., 1990.

${ }^{1} \mathrm{~V}$. C. Li and R. Ward, "A Novel Testing Technique for Post-peak Tensile Behavior of Cementitious Materials": pp. 183-95 in Fracture Toughness and Fracture Energy, Test Method for Concrete and Rock. Edited by H. Mihashi, H. Takahashi, and F. H. Wittman. A. A. Balkema, Rotterdam, Netherlands, 1989.

${ }^{19} \mathrm{C}$. K. Y. Leung and V. C. Li, "Determination of Fracture Toughness Parameter of Quasi-Brittle Materials with Laboratory-Size Specimens," J. Mater. Sci., 24, 854-62 (1989).

${ }^{20} \mathrm{~K}$. Rokugo, M. Iwasa, S. Seko, and W. Koyanagi, "Tension-Softening Diagrams of Steel Fiber Reinforced Concrete"; pp. 513-22 in Fracture of Concrete and Rock, Recent Developments. Edited by S. P. Shah. S. E. Swartz, and B. Barr. Elsevier Applied Science Publishers, London, U.K., 1989.

${ }^{2}$ TT. Hashida, "Tension-softening Curve Measurements for Fracture Toughness Determination in Granite"; pp. 47-55 in Fracture Toughness and Fracture Energy. Test Method for Concrete and Rock. Edited by H. Mihashi, H. Takahashi, and F. H. Wittman. A. A. Balkema, Rotterdam, Netherlands, 1989.

"2T. Hashida, "Evaluation of Fracture Processes in Granite Based on the Tension-Softening Model"; pp. 233-43 in Micromechanics of Failure of Quasibrittle Materials. Edited by S. P. Shah, S. E. Swartz, and M. L. Wang. Elsevier Applied Science, London, U.K.. 1990.

${ }^{2}$ K. P. Chong, V. C. Li, and H. H. Einstein, "Size Effects, Process Zone, and Tension Softening Behavior in Fracture of Geomaterials," Eng. Fract. Mech., 34 [3] 669-78 (1989).

${ }^{24} \mathrm{~A}$. Hillerborg; personal communications, 1985.

${ }^{25} \mathrm{O}$. Reyes, "Boundary Element Analysis of Non-linear Elastic Fracture Mechanics Problems"; Master's Thesis. Massachusetts Institute of Technology, Cambridge, MA, 1987.

${ }^{26} \mathrm{~J}$. R. Rice, "A Path Independent Integral and the Approximate Analysis of Strain Concentrations by Notches and Cracks," J. Appl. Mech., 35, 379-86 (1968).
${ }^{27}$ V. C. Li, "Post-Crack Scaling Relations for Fiber Reinforced Cementitious Composites," J. Mater. Civ. Eng., 4 [1] 41-57 (1992).

${ }^{28}$ S. Okuda, "Fracture Toughness Evaluation of Ceramics and Foam Glass Composites by Means of Tension-Softening Relation" (in Jpn.); Master's Thesis. Tohoku University, Sendai, Japan, 1991.

${ }^{29} \mathrm{~T}$. Hashida and $\mathrm{H}$. Takahashi, "Simple Determination of the Effective Young's Modulus of Rock by the Compliance Method," J.Test. Eval., 13 [1] 77-84 (1985).

"D. J. Green, "Fabrication and Mechanical Properties of Lightweight Ceramics Produced by Sintering of Hollow Spheres," J. Am. Ceram. Soc., 68 [7] 403409 (1985).

"J. C. Newman, Jr., "Stress Analysis of the Compact Specimen Including the Effects of Pin Loading"; pp. 105-21 in Fracture Analysis, ASTM STP 560. American Society for Testing and Materials, Philadelphia, PA. 1974.

${ }^{32} \mathrm{C}$. F. Shih, H. G. Dolorenzi, and W. R. Andrews, "Elastic Compliances and Stress Intensity Factors for Side Grooved Specimens," Int. J. Fract., 13, $544-48$ (1977).

${ }^{33}$ A. Hillerborg. "Analysis of a Single Crack"; pp. 223-49 in Fracture Mechanics of Concrete. Edited by F. H. Wittman. Elsevier, Amsterdam, Netherlands, 1983.

${ }^{M}$ L. M. Barker, "A Simplified Method for Measuring Plane Strain Fracture Toughness," Eng. Fract. Mech., 9, 361-69 (1977).

3s International Society for Rock Mechanics (F. Ouchterlony, Working Group Coordinator), "Suggested Methods for Determining the Fracture Toughness of Rock," Int. J. Rock. Mech. Min. Sci., 25, 71-96 (1988).

${ }^{*} \mathrm{H}$. Kodama, T. Suzuki, H. Sakamoto, and T. Miyoshi, "Toughening of Silicon Nitride Matrix Composites by the Addition of Both Silicon Carbide Whiskers and Silicon Carbide Particles," J.Am. Ceram. Soc., 73 [3] 678-83 (1990).

${ }^{37}$ F. Zok, O. Sbaizero, C. L. Hom, and A. G. Evans, "Mode I Fracture Resistance of a Laminated Fiber-Reinforced Ceramic," J. Am. Ceram. Soc., 74 [1] 187-93 (1991).

"T. Miyajima and M. Sakai, "Fracture Toughness for First Matrix Cracking of a Unidirectionally Reinforced Carbon/Carbon Composite Material," J. Mater. Res., 6 [11] 2312-17 (1991).

"R. Knehans and R. Steinbrech. "Memory Effect of Crack Resistance During Slow Crack Growth in Notched $\mathrm{Al}_{2} \mathrm{O}_{3}$ Bend Specimens," J. Mater. Sci. Lett., 1, 327-29 (1982)

${ }^{40} M$. V. Swain, "R-Curve Behavior in a Polycrystalline Alumina Material," J. Mater. Sci. Lett., 5, 1313-15 (1986).

"P. L. Swanson, C. J. Fairbanks, B. R. Lawn, Y. W. Mai, and B. J. Hockey, "Crack-Interaction Grain Bridging as a Fracture Resistance Mechanism in Ceramics: I, Experimental Study on Alumina," J. Am. Ceram. Soc., 70 [4] 279_ 89 (1987).

"2J. Rödel, J. F. Kelly, and B. R. Lawn, "In Situ Measurements of Bridged Crack Interfaces in the Scanning Electron Microscope,"J. Am. Ceram. Soc., 73 [11] 3313-18 (1990).

${ }^{4}{ }^{3}$ R. W. Steinbrech, A. Reich, and W. Schaarwächter, "R-Curve Behavior of Long Cracks in Alumina," J. Am. Ceram. Soc., 73 [7] 2009-15 (1990).

"M. Sakai, J. Yoshimura, Y. Goto, and M. Inagaki, "R-Curve Behavior of a Polycrystalline Graphite: Microcracking and Grain Bridging in the Wake Region," J. Am. Ceram. Soc., 71 [8] 609-16 (1988).

${ }^{4} \mathrm{~V}$. C. Li and E. Liang, "Fracture Processes in Concrete and Fibre-Reinforced Cementitious Composites," ASCE J. Eng. Mech. Div. 122 [6] 566-86 (1986).

${ }^{46} \mathrm{~F}$. Zok and C. L. Hom, "Large Scale Bridging in Brittle Matrix Composites," Acta Metall. Mater., 38 [10] 1895-904 (1990).

"J. L. Lorca and M. Elices, "Fracture Resistance of Fiber-Reinforced Ceramic Matrix Composites," Acta Metall. Mater., 38 [12] 2485-92 (1990).

${ }^{4} M$. D. Thouless and A. G. Evans, "Effects of Pull-Out on the Mechanical Properties of Ceramic-Matrix Composite," Acta Metall., 36 [31 517-22 (1988).

${ }^{49}$ V. C. Li and C. K. Y. Leung. "Theory of Steady State and Multiple Cracking of Random Discontinuous Fiber Reinforced Brittle Matrix Composite," ASCE J. Eng. Mech. Div., in press. 